\title{
Editorial
}

\section{Life Cycle Costing in LCM: Ambitions, Opportunities, and Limitations Discussing a Framework}

\author{
Gerald Rebitzer ${ }^{1 *}$ and David Hunkeler ${ }^{2}$ \\ ${ }^{1}$ Swiss Federal Institute of Technology, ENAC-GECOS, CH-1015 Lausanne, Switzerland \\ ${ }^{2}$ AQUA+TECH Specialties SA, CH-1283 La Plaine, Geneva, Switzerland
}

*Corresponding author (Gerald.Rebitzer@epfl.ch)

\section{Background}

During the 1992 United Nations Conference on Environment and Development, in Rio, sustainable development ${ }^{1}$ was put forth as an important task for the 21 st century. A key aspect of sustainable development was, and is, the consideration of ecological, economic, and social 'pillars', though without specifying the weighting of such priorities, indeed values. Perhaps the most relevant weakness of the generally accepted framework of sustainable development is that it is not directly applicable, and that it can contain 'everything and nothing'. Some critics have, further, referred to sustainable development as a 'buzzword for zero content'. Though these are provocative and extreme point of views, they certainly contain some aspects of truth, or at least concern.

Within the area of product-focused environmental management, life cycle management (LCM), attempts to put sustainable development into practice. LCM, with its toolbox and decision-oriented goals, seeks to render sustainability accessible, quantifiable, and operational. Therefore, the aforementioned three pillars of sustainable development can also be found in LCM. In this editorial, inspired by a discussion between members of the editorial board of Int J LCA (Walter Klöpffer, David Pennington), the co-chair of the SETAC Europe LCC Working Group (WG), Kerstin Lichtenvort, and the authors (also members of the editorial board, as well as co-chairs of the WG), a view on the ambitions, opportunities, and limitations of life cycle costing (LCC) in LCM, is given. The goal is to clarify important aspects of, and to propose a framework for, LCC. The authors want to thank the aforementioned experts as well as the SETAC Europe WG members, Wulf-Peter Schmidt and Stefan Seuring, for inspiring discussions, inputs, and critical comments, but have to stress that the elaborations are purely based on their views and do not express any consensus opinion of the SETAC LCC WG (see Rebitzer and Seuring 2003), though the deliberations within this group have also contributed to the findings presented in this paper.

\section{Conceptual Framework of Life Cycle Costing}

Prior to defining the authors' views on life cycle costing, some background on environmental assessment is required,

\footnotetext{
1 The Brundtland commission defined sustainable development as development that "meets the needs of the present without compromising the ability of future generations to meet their own needs" (WCED 1987).
}

at the minimum for economically oriented readers. Life cycle assessment (LCA), in its various forms and levels of detail from life cycle thinking to detailed LCAs, is the primary and established tool for assessing the environmental performance of a good or service ${ }^{2}$ within LCM. The inclusion of social aspects in LCM is still in its infancy (Klöpffer 2003), though this must clearly not be neglected and could be built on the 'tradition' of LCA via multi-stakeholder groups which must include firms, both large and small, Northern and Southern, researchers, NGOs, citizens/consumers, governments and, likely, religious/social groups. The development of LCC, currently, seems, though consensus remains lacking, to be somewhere in between the aforementioned stages of environmental and social assessments, respectively.

The general incentives and ideas behind LCC are elaborated in (Hunkeler and Rebitzer 2003) and will not be repeated here. Rather we seek to examine LCC from a conceptual perspective and in relation to the other core elements of LCM as well as to discuss what costs should be included in LCC. Fig. 1 represents the conceptual framework of LCC, based on the physical product life cycle, with which also the relationship of LCC to LCA and social assessments (e.g., including employment conditions and unemployment rates) in LCM can be explained.

In Fig. 1, one can differentiate between:

1) Internal Costs along the life cycle of a product, with 'internal' implying that someone (a producer, transporter, consumer or other directly involved stakeholder) is paying for the production, use, or end-of-life expenses and, thereby, it can be connected to a business cost, and, indeed, liability. This concerns all the costs and revenues within the economic system (inside the dashed lines as represented in Fig. 1).

2) External costs that are envisioned to include the monetized effects of environmental and social impacts not directly billed to the firm, consumer, or government, etc. that is producing, using, or handling the product. These are the so-named 'externalities' so popular in LCC and LCA debates, which are outside the economic system, though inside the natural and social system as illustrated in Fig. 1.

\footnotetext{
2 Goods and services or their utilities can be summarized under the term 'product' (WCED 1987).
} 


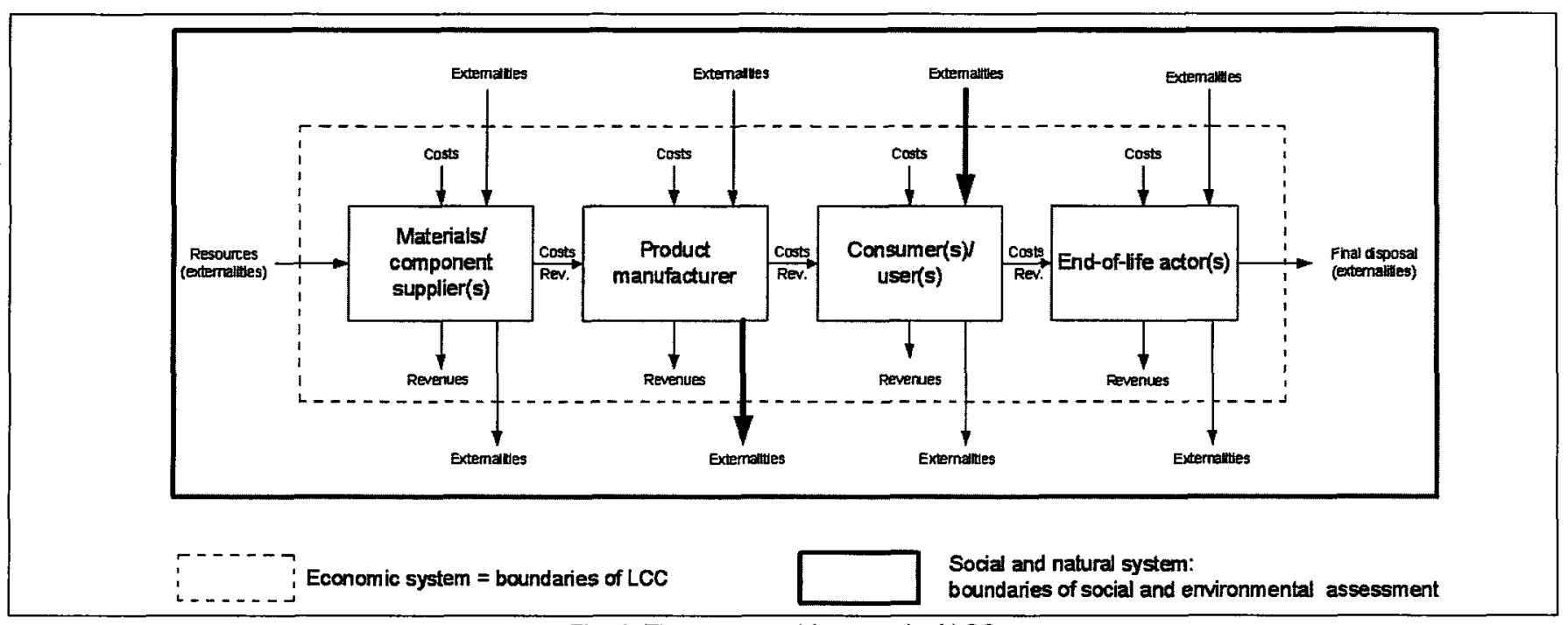

Fig. 1: The conceptual framework of LCC

In this context it is important to note that the terms and boundaries for economic, as well as social and natural systems, are not synonymous to the product system in LCA. For a common assessment of two or three of the LCM elements, the product system has to have the same system boundaries, as stressed by e.g. (Klöpffer 2003 and Schmidt 2003).

If one examines a perfectly free market, without any taxes or subsidies to account for externalities, LCC could focus only on the economic system if the following condition is satisfied: LCC is applied in conjunction with environmental and/or social assessments for the same product system with the same system boundaries.

\section{The Role of Taxes and Subsidies in the Framework and the Internalization of Externalities}

Under such an, albeit simplified, scenario, all externalities are covered by the other assessments within the LCM toolbox. On the other hand, if taxes and subsidies exist and they are fair ${ }^{3}$, or justifiable based on the collection of a social overhead based on a product's burden, then the economic system can be used as a simplification for the complete social and natural system. Therefore, if all externalities would be completely and perfectly covered by tax and subsidy mechanisms, nationally and supra-nationally, LCC would provide all the necessary information for LCM, rendering systematic environmental and other assessments unnecessary for all but new products.

Clearly, the aforementioned macroeconomic assumptions are oversimplified, and, in particular, the latter (complete coverage of externalities by tax and subsidy mechanisms) does not approach practice. If one assumes the tax system is valid for certain products, and not so for others, from socio-environ-

\footnotetext{
3 A simple, though relevant, example is the cost, to the user, of cigarettes. Clearly, the high taxes contribute to the social and environmental overhead of smoking. However, the price of a box of cigarettes, which typically is 3 Euro in Europe, is a lucrative tax means which may over- or underestimate the actual externalities. If these taxes are fair, from a public health and environmental perspectives, then the externalities are built in. If they are unfair, then externalities can either be unaccounted for, or double counted.
}

mental perspectives, then integrating externalities as suggested by e.g. (White et al. 1996 and Shapiro 2001), could, theoretically, provide the complimentary information needed to consider the social and environmental consequences of a decision. This would lead to a full aggregation of the three pillars of $\mathrm{LCM}^{4}$ in monetary units. Though such an aggregation might be desirable from a scientific point of view, the authors see this as contradictory to the goals of LCM (i.e. making life cycle approaches transparent, understandable, operational, and readily applicable in routine decision-making). This is relevant not only in SMEs and in emerging regions, but also for multinational companies, since it drastically increases the complexity of the analyses and introduces additional value choices and major methodological problems of other disciplines as e.g. macroeconomic cost-benefit-analysis.

\section{The Scope and Definition of LCC}

Concluding the discussion of the question "what to include in LCC within LCM?", it seems appropriate to base LCC, as long as it framed by independent other assessments such as LCA, on the assumption of a primarily unregulated market (see above), even if this includes some double counting for the external affects actually internalized via taxes or subsidies and introduces additional uncertainties. This implies that only internal and internalized costs should be accounted for in LCC. Exceptions are cases where externalities occur that are shown, based on preliminary or prior analyses, to introduce significant (potential) costs in the future due to internalization via regulatory measures (e.g., anticipated $\mathrm{CO}_{2}$ taxes, renewable energy subsidies). The bold arrows in Fig. 1 schematize such an example wherein a selected number of externalities have to be considered in the LCC in order to include these risks.

Building on this approximation of a free (unregulated) market, one can define LCC as an assessment of all costs associated with the life cycle of a product that are directly covered by the any one or more of the actors in the product life cycle (supplier, producer, user/consumer, EOL-actor), with complimentary inclusion of externalities that are anticipated to

${ }^{4}$ Environmental, economic, and social issues form the three pillars. 
be internalized in the decision-relevant future (modified on the basis of the definition of Blanchard and Fabrycky 1998). In this sense, LCC can define the feasibility of an option with good environmental and social performance. In other words, if several options for managing the life cycle of a product are compared and one option is preferable due to environmental and social benefits, this option cannot be unsustainable in the economic sense, as long as someone in the economy produces and markets the product with success. This also implies that life cycle costing, without additional assessments, cannot serve as a sole indicator for good (sustainable) LCM practice, unless there is a validated correlation of low life cycle costs to low environmental and social impacts for specific products or product groups.

The preceding definition, therefore, defines LCC as a method which accounts for only those externalities, above a threshold (i.e., they are significant to the decision), that are anticipated to become internal costs. It does not, as some advocate, include full double accounting (cost and environmental impacts) nor does it neglect externalities entirely, as others prefer.

\section{Limitations of LCC}

An important qualification to the prior definition (in bold) is that LCC is not a method for financial accounting. Rather, it is a cost management method with the goal of estimating the costs associated with the existence of a product, as LCA is not a method for environmental accounting of the environmental impacts of a specific industrial site or operation. Returning to the issue of taxes and subsidies, partial accounting will not create an invalid result, in LCA or LCC, nor in their complimentary application in LCM, if the inventory or financial data included contain the majority of burdens, whether environmental or economic. Furthermore, the assessed product system must have the same boundaries for both metrics (see above).

\section{Perspectives in LCC}

One heavily debated issue in LCC is the question whose costs one is accounting for. Are the costs of the user/consumer, of the producer, or the waste management operator, to give some examples, the relevant ones? This is caused by existence of value-added and margins, which have no counterparts in LCA. Therefore, the cost of one actor (e.g., the consumer, who buys a product) is the revenue for another one (here for the product manufacturer, if one neglects the trade sector for reasons of simplicity). This also has consequences for the necessary level of detail. If the perspective of the assessment is that of the user/consumer [see part c) in Fig. 2], the costs within the boundaries of the other organi-

a) Product manufacturer

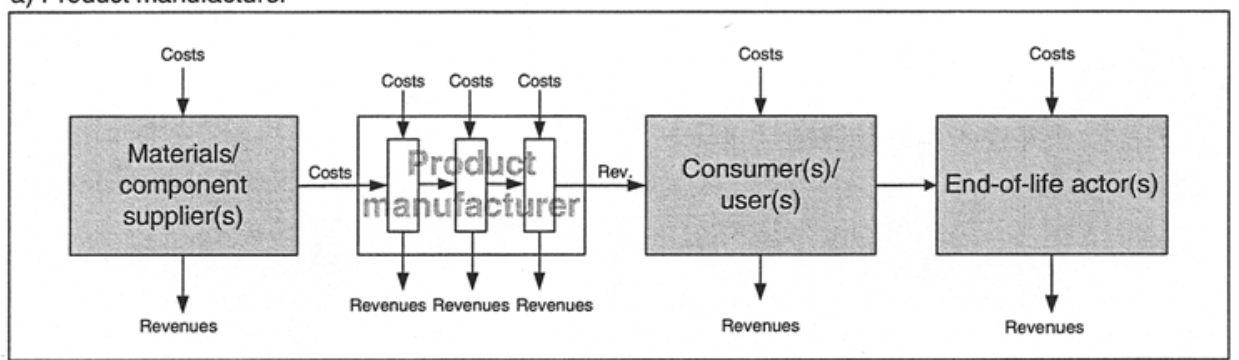

b) Product manufacturer and supply chain (supply chain integration)

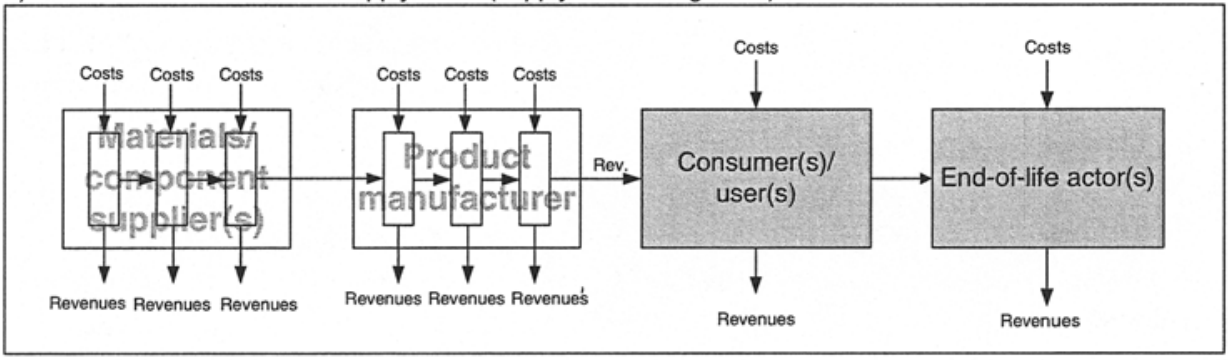

c) Consumer(s)/users

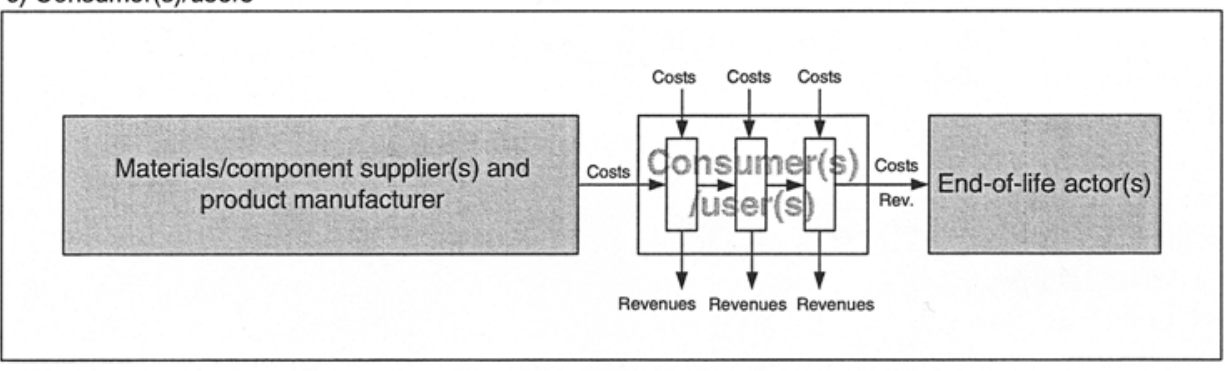

Fig. 2: Different perspectives in LCC (non-exhaustive examples) 
zations/actors can be viewed as a black box, without requiring any differentiation. Of specific interest, however, are the specific costs and revenues associated with the use of the product (e.g., introductory and energy costs, maintenance, re-selling of product). On the other hand, if a manufacturer seeks to optimize the life cycle costs, the detailed process costs that can be allocated to a product within the company are the major focus (e.g., in the form of activity-based-costing). In this case, the other cost elements in the life cycle require less detail [see part a) in Fig. 2]. Part b) in Fig. 2 represents a case where the level of detail within different actors/organizations is important. This is the case, if e.g. the supply chain is integrated by acquisition of the supplier or by supply chain coordination efforts (Seuring 2002). The notion of value added requires one to consider both costs and revenues in each stage, for LCC (see also Fig. 1).

\section{Relation of LCC to LCA}

If one relates LCC to life cycle inventories, and this is a strong recommendation of many (see e.g. Huppes 2003, Norris 2001, Rebitzer 2002), then it must be based on the physical life cycle of the good or service. This implies the inclusion of, specifically, a product's material, energy and service flows from acquisition through production, transport, use, disposal, and for very durable installations such as nuclear reactors, dismantling and long term disposal. In addition to the costs caused by physical processes and their associated material and energy flows identified by the life cycle inventory analysis step of LCA, expenses such as labor costs or costs for utilizing knowledge (e.g., patents), transaction costs (e.g., information flows), as well as marketing expenses have to be considered (Rebitzer 2003). For example, all costs for research and development, which are not directly linked to material flows, have to be integrated. It has been shown that the life cycle inventory of an LCA is an excellent basis for identifying and allocating all of the aforementioned costs in an efficient manner (Rebitzer 2003). However, challenges such as estimating and discounting future costs and revenues (Schmidt 2003) as well as aligning data per functional unit with financial data (Huppes 2003) remain to be solved and are therefore intensively discussed in the LCC WG of SETAC. Overall, a general LCC guidance, similar to the ISO 14040 series for LCA, seems to be desirable.

\section{Conclusions and Outlook}

Life cycle costing, to be used in LCM, must be based on a systematic analysis that is complimentary to and consistent with parallel environmental and social assessments. In this way it serves as an efficient measuring instrument for estimating the economic feasibility of changes required to move towards sustainable development. It may be based on life cycle inventory methods, though not without inclusion of some aspects traditionally not dealt with in LCA (or assumed to be of zero impact) and addressing issues of data compatibility in regards to level of aggregation and time dependency. Full aggregation of all internal costs and externalities, within LCC, though perhaps desirable for some, seems to be outside the goals and scope of LCM, due to the practical problems involved in doing such analyses and the lacking acceptation ${ }^{5}$. As noted, those externalities clearly above a given threshold, which itself is a controversial issue, and which are anticipated to be internalized, should be included. With this editorial the authors aim to bring clarification to the field, and also to provoke further discussions that might be fruitful to the development of LCC. The authors encourage a wide discussion, and open the forum to all, as we attempt to continue on the important task of establishing LCC, so obviously linked to political decisions, economic requirements, and societal motivations.

${ }^{5}$ The aggregation of LCC and LCA to one indicator via monetization methods, with its potential benefits and drawbacks, is another issue and not discussed in this paper.

\section{References}

Blanchard B, Fabrycky WJ (1998): Systems Engineering and Analysis. Prentice Hall, Upper Saddle River, New Jersey, USA, pp 506

Hunkeler D, Rebitzer G (2003): Life Cycle Costing - Paving the Road to Sustainable Development? (Editorial). Int J LCA 8 (2) 109-110

Huppes G (2003): The Simple Analytics of Life Cycle Costing in Sustainability Analysis. Presentation at the SETAC-Europe Annual Meeting in Hamburg, Germany, 27 April to 01 May 2003

Klöpffer W (2003): Life Cycle Based Methods for Sustainable Product Development. Int J LCA 8 (3) 157-159

Norris GA (2001): Integrating Life Cycle Cost Analysis and LCA. Int J LCA 6 (2) 118-120

Rebitzer (2002): Integrating Life Cycle Costing and Life Cycle Assessment for Managing Costs and Environmental Impacts in Supply Chains. In: Seuring S, Goldbach, M (eds.): Cost Management in Supply Chains. Physica-Verlag, Heidelberg, Germany, p 128-146

Rebitzer G (2003): Life Cycle Costing - The Economic Pillar of Sustainability, Introduction of Methodology and Application to Waste Water Treatment. Environmental Progress, forthcoming

Rebitzer G, Seuring S (2003): Methodology and Application of Life Cycle Costing. Int J LCA 8 (2) 110-111

Schmidt WP (2003): Life Cycle Costing as Part of Design-forEnvironment - Environmental Business Cases. Int J LCA 8 (3) 167-174

Seuring S (2002): Supply Chain Costing - A Conceptual Framework. In: Seuring S, Goldbach, $M$ (eds.): Cost Management in Supply Chains. Physica-Verlag, Heidelberg, Germany, $\mathrm{p}$ $15-30$

Shapiro KG (2001): Incorporating Costs in LCA. Int J LCA 6 (2) 121-123

WCED - World Commission on Environment and Development (1987): Our Common Future (The Brundtland Report). Oxford University Press, Oxford, UK

White AL, Savage D, Shapiro KG (1996): Life-Cycle Costing Concepts and Application. In: Curran MA (ed.): Environmental Life-Cycle Assessment. McGraw-Hill, New York, USA, p $7.1-7.19$ 